\title{
Erosive Degradation Study of Concrete Augmented by Mussel Shells for Marine Construction
}

\author{
Carolina Camba ${ }^{1}$, José Luis Mier ${ }^{1}$, Luis Carral ${ }^{1, *} \mathbb{B}$, María Isabel Lamas ${ }^{1}{ }^{\circledR}$, José Carlos Álvarez ${ }^{1}$, \\ Ana-María Díaz-Díaz ${ }^{1}\left(\mathbb{D}\right.$ and Javier Tarrío-Saavedra ${ }^{2} \mathbb{B}$
}

1 Escola Politécnica Superior de Ferrol, Universidade da Coruña, Rúa Mendizabal, 15403 Ferrol, Spain; carolina.camba@udc.es (C.C.); jose.mier@udc.es (J.L.M.); isabel.lamas.galdo@udc.es (M.I.L.); carlos.alvarez@udc.es (J.C.Á.); ana.ddiaz@udc.es (A.-M.D.-D.)

2 MODES Group, CITIC, Department of Mathematics, Escola Politécnica Superior, Universidade da Coruña, 15403 Ferrol, Spain; javier.tarrio@udc.es

* Correspondence: 1carral@udc.es

Citation: Camba, C.; Mier, J.L.;

Carral, L.; Lamas, M.I.; Álvarez, J.C.; Díaz-Díaz, A.-M.; Tarrío-Saavedra, J.

Erosive Degradation Study of

Concrete Augmented by Mussel

Shells for Marine Construction. J. Mar.

Sci. Eng. 2021, 9, 1087. https://

doi.org/10.3390/jmse9101087

Received: 23 August 2021

Accepted: 29 September 2021

Published: 5 October 2021

Publisher's Note: MDPI stays neutral with regard to jurisdictional claims in published maps and institutional affiliations.

Copyright: (c) 2021 by the authors. Licensee MDPI, Basel, Switzerland. This article is an open access article distributed under the terms and conditions of the Creative Commons Attribution (CC BY) license (https:/ / creativecommons.org/licenses/by/ $4.0 /)$.
Abstract: This work proposes a green material for artificial reefs to be placed in Galicia (northwest Spain) taking into account the principles of circular economy and sustainability of the ecosystem. New concrete formulations for marine applications, based on cement and/or sand replacement by mussel shells, are analyzed in terms of resistance to abrasion. The interest lies in the importance of the canning industry of Galicia, which generates important quantities of shell residues with negative environmental consequences. Currently, the tests to determine the abrasion erosion resistance of concrete on hydraulic structures involve large and complex devices. According to this, an experimental test has been proposed to estimate and compare the wear resistance of these concretes and, consequently, to analyze the environmental performance of these structures. First, a numerical analysis validated with experimental data was conducted to design the test. Subsequently, experimental tests were performed using a slurry tank in which samples with conventional cement and sand were partially replaced by mussel shell. The abrasive erosion effect of concrete components was analyzed by monitoring the mass loss. It shows an asymptotic trend with respect to time that has been modeled by Generalized Additive Model (GAM) and nonlinear regression models. The results were compared to concrete containing only conventional cement and sand. Replacing sand and/or cement by different proportions of mussel shells has not significantly reduced the resistance of concrete against erosive degradation, except for the case where a high amount of sand $(20 \mathrm{wt} . \%)$ is replaced. Its resistance against the erosive abrasion is increased, losing between 0.1072 and $0.0310 \mathrm{wt} . \%$ lower than common concrete. In all the remaining cases (replacements of the 5-10 wt.\% of sand and cement), the effect of mussel replacement on erosive degradation is not significant. These results encourage the use of mussel shells in the composition of concrete, taking into account that we obtain the same degradation properties, even more so considering an important residue in the canning industry (and part of the seabed) that can be valorized.

Keywords: marine construction; artificial reefs; concrete; abrasive erosion test; computational fluid dynamics modeling; degradation; statistical learning; GAM; functional data analysis

\section{Introduction}

Marine habitats can be modified through the use of artificial reefs that provide many functions: improvement of fishery production, conservation of resources, restoration of the marine substrate, and new applications such as tourism and recreational use of the sea [1,2]. The traditional material for the construction of these structures is concrete due to its high durability, stability, and low cost [3]. Concrete is basically composed of cement, sand, and gravel. Sixty to eighty percent of the concrete volume corresponds to natural aggregates (sand and gravel), which leads to a pressure on the surrounding ecosystems. The use of aggregates in concrete can be reduced through the use of waste from maritime 
industries. To this end, they must be processed in such a way that they can be used to replace fine and coarse aggregate. The chosen materials used in its construction must not pollute the environment by leaching and erosion in contact with seawater in accordance with the Oslo and Paris (OSPAR) Convention for the Protection of the Marine Environment of the Northeast Atlantic [4]. Consequently, this new type of concrete will be an interesting option in other marine applications [5-8].

A specific case of marine structures are the artificial reefs, a potential field of application of the present study. Although the use of submerged structures to increase the catch of fish and other animals seems to be a very old practice, it was not until the 1960s that these structures began to be studied from a scientific point of view [9]. Since this decade, the number of studies on artificial reefs has grown exponentially, largely due to the growing needs of marine biodiversity regeneration. This means that the field of study is relatively new and highly demanding of new studies due to socioeconomic needs, and the largest proportion of studies about artificial reefs corresponds to recent years. As indicated in [9], studies about artificial reefs are currently developed in the frameworks of ecology, engineering, socioeconomics, management, animal behavior, environmental impact, and oceanography. Within the field of engineering (the scope of this study), the choice of materials is very important. The most used material is concrete, as shown above (in addition, it tends to provide greater fixation for organisms), above others such as wood, metal, polymers, or rocks, among others. It is important to note that, in recent times, there has been a trend to add industrial by-products $[10,11]$ and biogenic material such as bivalve shells to concrete [12-14]. This is the case of the present study, where mussel shells, residues of the can industry, are introduced in concrete. It is also important to highlight that one of the challenges of this domain is to reduce the gap between theory and practice and increase the interdisciplinary studies that include models [9]. Works such as [15] and the present study (involving numeric analysis, statistics, material science) intend to contribute to achieve this objective.

Concrete is mainly made of cement, sand, and gravel. An alternative is the use of waste from the canning industry such as mussel shells. Carral et al. $[13,16]$ analyzed this possibility and established the alternative to substitute up to $10 \%$ cement or $20 \%$ sand. Galicia (northwest Spain) is the first shell producer in Europe and the third in the world, thus generating an important quantity of shells each year [17]. Mussel shells currently represent a problem in this region, so there is a great interest in reusing them. Before use, a series of treatments must be carried out that consists of washing with fresh water to eliminate its saline content, heating at high temperatures to eliminate moisture and organic matter, and grinding into different sizes depending on its subsequent use [18].

The mussel shell is characterized by having a high content of calcium carbonate (>95\% in weight). This compound occurs mainly in the form of calcite with significant amounts of aragonite. Various studies have shown that the size of the $\mathrm{CaCO}_{3}$ particles is smaller than those of Portland cement, so that the porosity and permeability of concrete to marine aggressive ions (chloride and sulphate) would decrease if these were used as a filling material in concrete [19-21]. However, the incorporation of these residues has its limitations. Various studies have concluded that the density and compressive strength of concrete decrease with increasing weight percentage of marine shells incorporated [22,23].

An important aspect to take into account regarding artificial reefs and marine structures in general is their degradation by abrasive-erosive wear. This phenomenon is accentuated in the marine environment by the presence of aggressive ions for concrete such as chloride and, to a lesser extent, sulfate and the existence of cyclical mechanical impacts with abrasive particles in suspension (silt, sand, pebbles, cobbles). The resistance to wear depends on the hardness of the concrete, which is determined by the type of cement, aggregate nature, granulometry, water/cement ratio, and cement/aggregate adherence. Resistance to abrasion erosion is determined by the ease of formation of microcracks in its structure, apart from the ones that appear naturally in it. The area most vulnerable to 
cracking during wear processes is the interfacial transition zone (ITZ), where the porosity of the cement is greater than in the rest of the matrix [24,25].

According to [8], the mass loss promoted by the abrasive erosion in concrete comprises three stages. (1) First, the pressure of the water molecules promotes an initial abrasion. (2) Then, the impacts of solids transported by water promote a removal of the material. (3) Finally, the removement of aggregates takes place due to scratching and shearing.

The deterioration of concrete structures is palpable over a relatively long period of time (months or years). For this reason, laboratory tests are needed to speed up the process to evaluate the durability of concrete to erosion.

For a certain time, it was considered that the wear resistance of concrete could be determined from its compressive strength through a potential function $W R=\sigma c X$, where $W R$ is the weight loss due to wear, $\sigma c$ the compressive strength, and $x$ a constant. Currently, this assertion is questioned by several studies $[25,26]$.

The study of the underwater erosion of concrete structures by abrasive particles in suspension can be carried out through the American Society for Testing and Materials (ASTM) C1138 [27] standard. However, this standard is used to evaluate wear caused by friction, but not by impact of the particles. In addition, the dimensions of the specimens (305 mm radius and $102 \mathrm{~mm}$ high cylinders) make handling difficult. Various authors have tried to develop alternative tests to ASTM C1138 [28-33]. Their results differ from one another depending on how they simulate actual service conditions. They also involve large and complex devices. Regarding the service conditions, it is important to note that materials submerged in the seabed or riverbed may be subjected to the abrasive-erosive effect of three types of sediment layers. Depending or their size, from the smallest to largest transported particles, these layers are bed load, suspended load, and wash load. The movements of the particles (salting, rolling, and sliding) that compose the bed load are the cause of the most important wear phenomena.

\section{Materials and Methods}

The main objective of the present work is to analyze the resistance to abrasion of different types of concrete made by mussel shells as potential substitutes of cement and sand. For this purpose, we need to define an erosive abrasion test that allows us to compare the different concretes, by simulating the impact of particles in marine environment. The application is focused on marine constructions, specifically artificial reefs.

Taking into account the important amount of mussel shell residues generated by the Galician canning industry, mussel shells are proposed as alternative materials to partially substitute cement and sand. A computational fluid dynamics (CFD) model was conducted to design the test. Subsequently, the experimental analysis to analyze the abrasive erosion release of concrete components was carried out in the laboratory. It consists of a slurry tank in which samples with conventional cement and sand partially replaced by mussel shell were tested. The results were compared to concrete containing only conventional cement and sand.

The present experimental setup differs from ASTM C1138 by replacing the steel balls with an abrasive material (silica sand), whose characteristics are similar to those found in seabed particles. In addition, the geometry of the specimens has been modified to resemble that used in the artificial reef to take into account the existence of edges that are not present in the ASTM standard. Therefore, this experimental testing is defined for the specific case of our artificial reefs prototypes and, in order to design and validate that the testing set-up reproduce the real marine ambient conditions, a computational fluid dynamics model was conducted.

\subsection{Methodology}

The following four concrete samples with different compositions were analyzed. Three repetitions, with initial sample weights ranging from $2127 \mathrm{~g}$ to $2368 \mathrm{~g}$, were realized.

- B: conventional concrete basically made by cement, sand, and gravel. 
- C: $10 \mathrm{wt} . \%$ of the cement is substituted by shells.

- A: $20 \mathrm{wt} . \%$ of the sand is substituted by shells.

- AC: $4-5 \mathrm{wt} . \%$ of the cement is substituted by shells, and $10 \mathrm{wt} . \%$ of the sand is substituted by shells.

The same materials were used in all of them: cement IV/A(V) 52.5N/SR (LafargeHolcim, Madrid, Spain), aggregates of 0-20 mm and 0-40 mm, and Sika ${ }^{\circledR}$ Visconcrete-3425 (Sika, Alcobendas, Spain).

Concrete $\mathrm{B}$ is a traditional one with cement, water, and aggregates in the proportions indicated in Table 1. In concrete C, $20 \mathrm{wt} . \%$ of the concrete B cement was replaced by mussel shell in powder form. In concrete A, $10 \mathrm{wt} . \%$ of the aggregates were replaced by crushed mussel shell with a granulometry similar to that of the substituted aggregates. Finally, in concrete AC, part of the cement ( $5 \mathrm{wt} . \%)$ and part of the aggregates (10 wt.\%) were replaced by mussel shell powder. The same amount of plasticizer was added to all the concretes.

Table 1. Concrete compositions (wt.\%).

\begin{tabular}{ccccc}
\hline & Concrete B & Concrete C & Concrete A & Concrete AC \\
\hline Water & 7.69 & 7.69 & 7.69 & 7.69 \\
Fine aggregates (sand) & 33.90 & 33.90 & 27.12 & 30.51 \\
Coarse aggregates (gravel) & 44.94 & 44.94 & 35.95 & 40.45 \\
Cement & 13.47 & 12.12 & 13.47 & 12.79 \\
Mussel shell aggregate & 0.00 & 0.00 & 15.77 & 7.88 \\
Mussel shell cement & 0.00 & 1.27 & 0.00 & 0.68 \\
Total & 100.00 & 100.00 & 100.00 & 100.00 \\
\hline
\end{tabular}

Before using the mussel shells, a series of treatments must be carried out: washing with fresh water to eliminate its saline content, heating at high temperatures to eliminate humidity and organic matter, and crushing them into different sizes depending on their later use. Table 2 shows the particle size distribution after crushing determined by a Micromeritics laser granulometer. Specific area was $5.7 \mathrm{~cm}^{2} / \mathrm{g}$ and density was $2.70 \mathrm{~g} / \mathrm{cm}^{3}$. Both were determined by an ASAP 2020 Micromeritics BET (Micromertrics Instruments Corporation, Barcelona, Spain) analyzer. All the concrete samples were cured for 28 days immersed in water at $20^{\circ} \mathrm{C}$.

Table 2. Particle size distribution of crushed mussel shell.

\begin{tabular}{ccccccccc}
\hline $\begin{array}{c}\text { Particle Size Interval } \\
(\boldsymbol{\mu m})\end{array}$ & $<\mathbf{2}$ & $\mathbf{2 - 5}$ & $\mathbf{5 - 1 0}$ & $\mathbf{1 0 - 2 0}$ & $\mathbf{2 0 - 4 5}$ & $\mathbf{4 5 - 6 3}$ & $\mathbf{6 3 - 1 2 5}$ & $\mathbf{1 2 5 - 2 5 0}$ \\
\hline wt. \% & 22.0 & 10.9 & 6.4 & 9.6 & 23.1 & 14.0 & 13.8 & 0.2 \\
\hline
\end{tabular}

Once the curing process is completed, the concrete is tested in a slurry device as shown in Figure 1. Four baffles oriented $90^{\circ}$ to each other are added in order to increase the turbulent regime of the fluid. The tank is $293 \mathrm{~mm}$ in diameter and $196 \mathrm{~mm}$ in height. The samples are cubic with edges of $100 \mathrm{~mm}$. They are placed in the center of the bottom of the tank with the edges in front of the baffles. The samples are held to the bottom to prevent their movement during the test and impact with the walls of the tank. The rod stirrer is placed $20 \mathrm{~mm}$ from the upper face of the sample. Solutions of $350 \mathrm{~g}$ of $\mathrm{NaCl}$ per liter of water are prepared to reproduce the salinity of seawater. Silica sand with a particle size of $0.1-0.6 \mathrm{~mm}$ with a pulp density of $1286 \mathrm{~kg} / \mathrm{m}^{3}$ is used as abrasive, corresponding to a solid weight fraction of $35.7 \%$. 


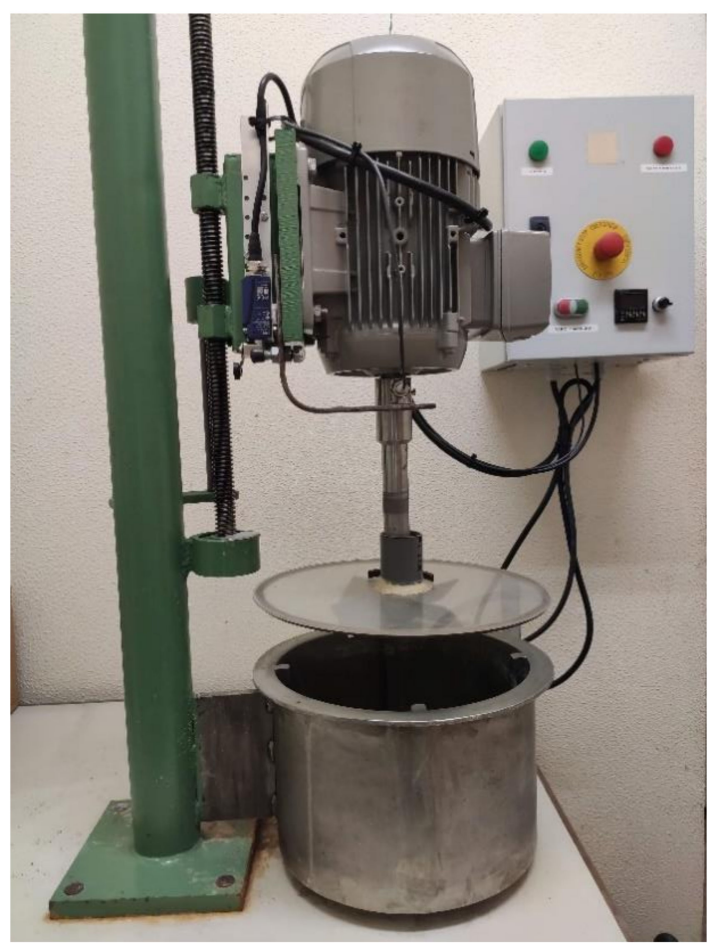

Figure 1. Slurry device.

The test time took $11 \mathrm{~h}$. The wear was determined by a loss of mass. Sample weight was measured at $1 \mathrm{~h}, 2 \mathrm{~h}, 4 \mathrm{~h}, 7 \mathrm{~h}$, and $11 \mathrm{~h}$. The duration of the test is $11 \mathrm{~h}$ because it was previously observed that above this time, there was a significant loss of mass.

The data obtained were analyzed through a statistical analysis. The first step is to define the variable that best defines the degree of erosive degradation, such as the mass loss measured in percentage with respect to the initial mass. Specifically, the response variable is the concrete weight loss percent due to erosive degradation (measured in an interval between 0 and $11 \mathrm{~h}$ ) of a specific accelerated life testing program developed in a laboratory. In this way, the effect of erosion degradation can be compared independently of the initial mass of the specimen. On the other hand, the independent variables or predictors are the time and a factor that accounts for the proportion of sand and cement replaced by mussel shells at four levels:

- B: The control level, defined by 0 wt. $\%$ cement and sand substitution.

- C: $10 \mathrm{wt} . \%$ of cement is replaced by mussel.

- A: $20 \mathrm{wt} . \%$ of sand is replaced by mussel.

- AC: $5 \mathrm{wt} . \%$ of cement and $10 \mathrm{wt} . \%$ of sand are replaced by mussel.

\subsection{Validation of the CFD Model}

The design of the tank used in this work is based on the device used by Messa et al. [28] in the study of the erosion-abrasion of a waterborne particle on submerged concrete. Figure 2 shows the experimental setup, which consists of a steel cylindrical tank filled with water. A concrete specimen is placed at the bottom. An agitator keeps the water and the abradant in rotary motion. Four lateral baffles are introduced in order to enhance turbulence. The abradant consists of $1 \%$ volume fraction of silica sand particles with $1.5 \mathrm{~mm}$ diameter. 


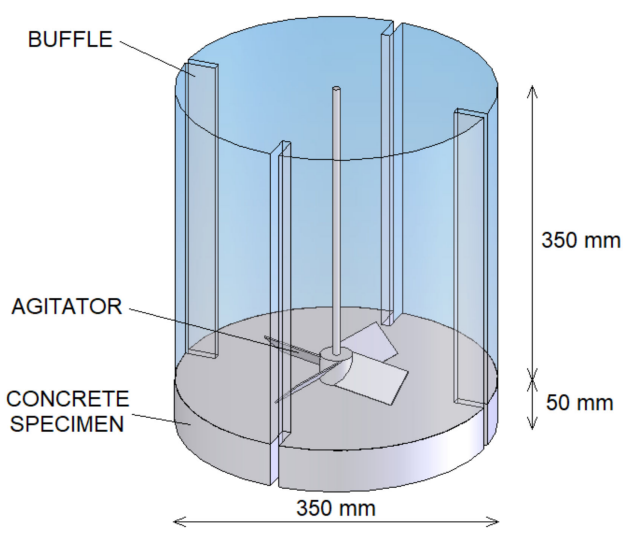

Figure 2. Experimental setup.

The liquid-particle flow was modelled based on the Euler-Euler approach. The mass and momentum equations for each phase are given by Equations (1) and (2), respectively. The turbulence was modeled through the $k-\varepsilon$ model:

$$
\begin{gathered}
\frac{\partial}{\partial t}\left(\alpha_{q} \rho_{q}\right)+\nabla \cdot\left(\alpha_{q} \rho_{q} \vec{v}_{q}\right)=0 \\
\frac{\partial}{\partial t}\left(\alpha_{q} \rho_{q} \vec{v}_{q}\right)+\nabla \cdot\left(\alpha_{q} \rho_{q} \vec{v}_{q} \vec{v}_{q}\right)=-\alpha_{q} \nabla p+\nabla \cdot \tau_{q}+\alpha_{q} \rho_{q} \vec{g}
\end{gathered}
$$

where $\alpha_{q}, \rho_{q}, v_{q}$, and $\tau_{q}$ are the volumetric fraction, density, velocity, and stress-strain tensor of phase $\mathrm{q}$, fluid, or particles, respectively.

Turbulence was treated through the $k-\varepsilon$ turbulence model. The CFD computations were performed using the software Ansys Fluent. The Pressure-Implicit with Splitting of Operators (PISO) algorithm was chosen for pressure-velocity coupling, and a second order upwind scheme was employed to discretize the governing equations. The temporal treatment was solved through an implicit method. The computational mesh is shown in Figure 3. Several size meshes were tested in order to verify its adequacy. The mesh size was refined near the blades. Two zones were differenced, rotating and static. The rotating zone, indicated in yellow color in Figure 3, is a cylinder that embraces the blades. The static zone, in black color, is the remaining region. A sliding mesh technique was adopted to interpolate the values at the boundary between the rotating and static domains.

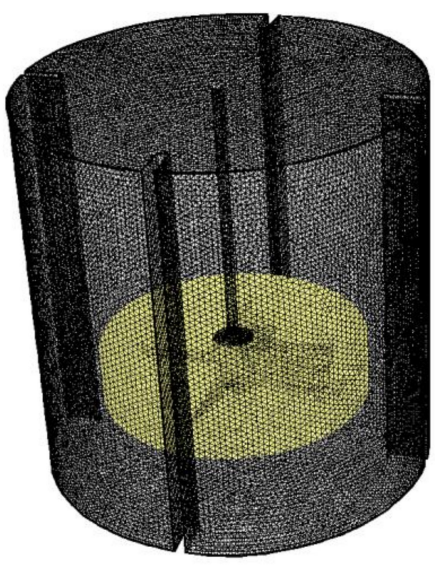

Figure 3. Computational mesh.

The velocity field corresponding to $600 \mathrm{rpm}$ is shown in Figure 4. As can be seen, important velocities are promoted on the surface of the concrete specimens, which will cause abrasion. 


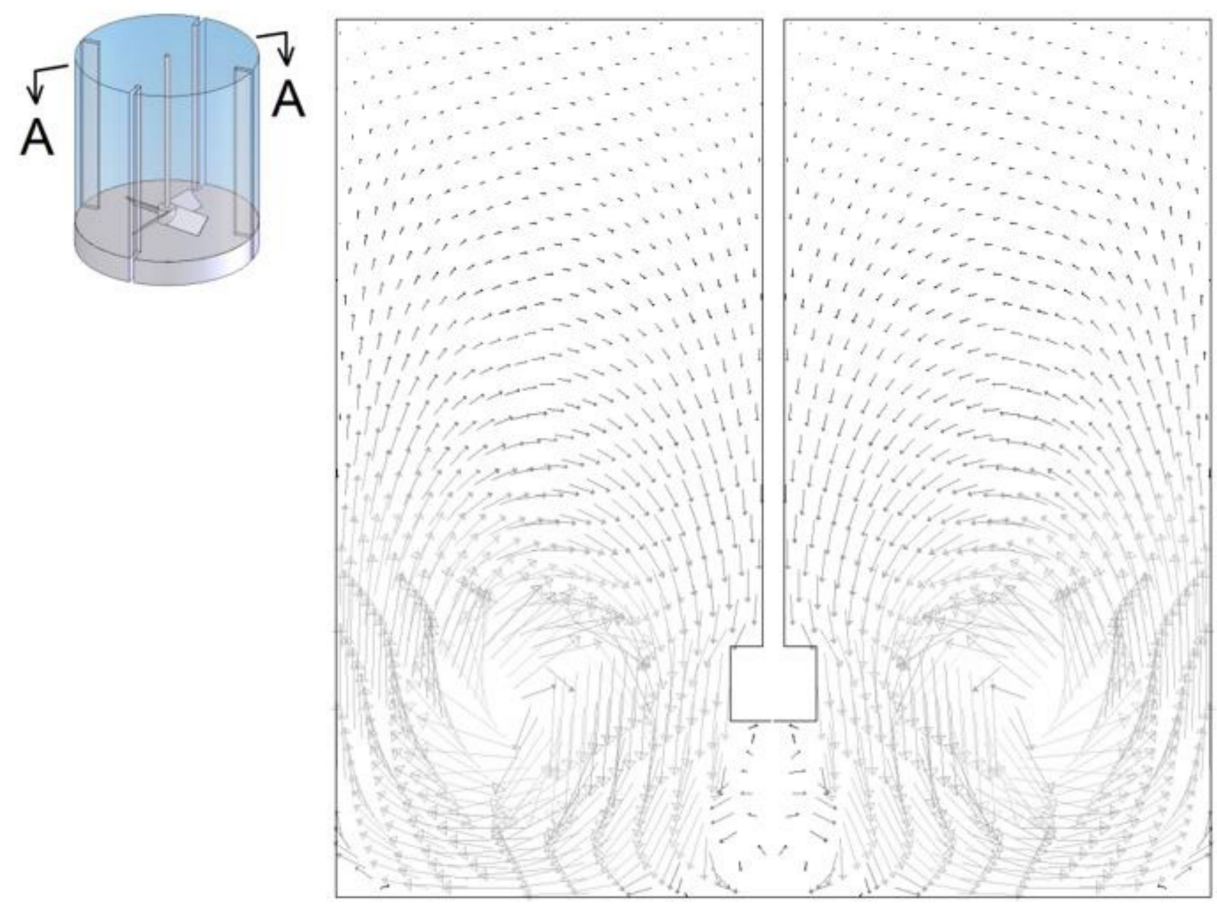

Figure 4. Velocity field in the A-A middle plane.

The experimental results are shown in Figure 5, which shows consistency with the experimental results. As can be seen, an annular zone where particle impingements are likely to occur is observed.

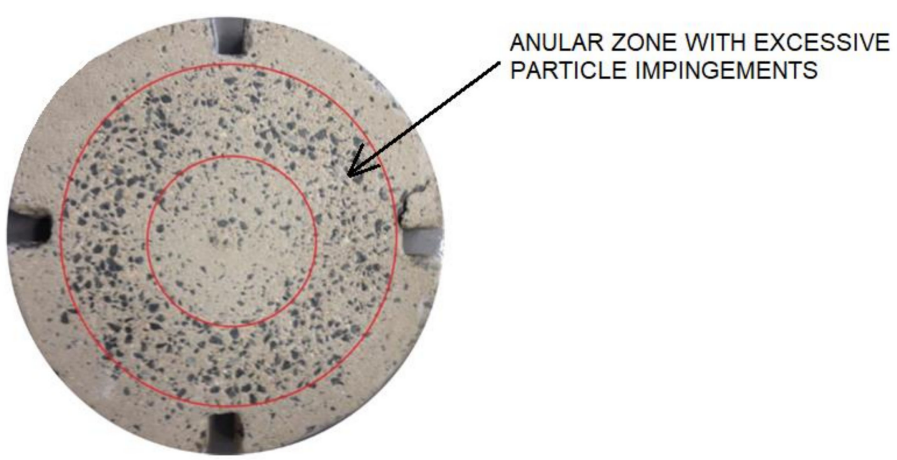

Figure 5. Surface of specimen after $24 \mathrm{~h}$ (reprinted from ref. [20]).

\subsection{Application of the CFD Model to the Present Analysis}

In order to reproduce the wear mechanisms of marine environments, it is necessary to analyze regions in which the particles impinge against the samples. The numerical model will be employed to analyze how the blades are capable of pushing the particles against the sample. Figure 6a shows the geometry of the test employed to realize the experiments and Figure $6 \mathrm{~b}$ the computational mesh to simulate them numerically. The experiments were realized under $450 \mathrm{rpm}$ and using a 0.00113 initial volume fraction. The results of the CFD model application (Figure 7) show that this specific experimental setup is able to reproduce the ambient conditions of materials submerged in marine environment. 


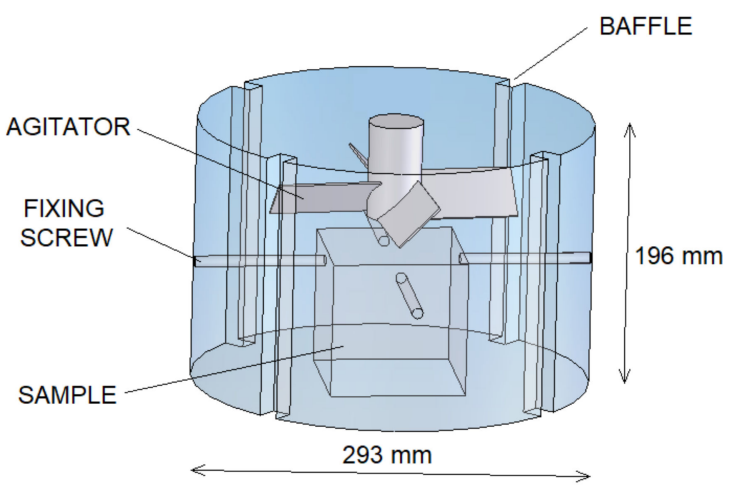

(a)

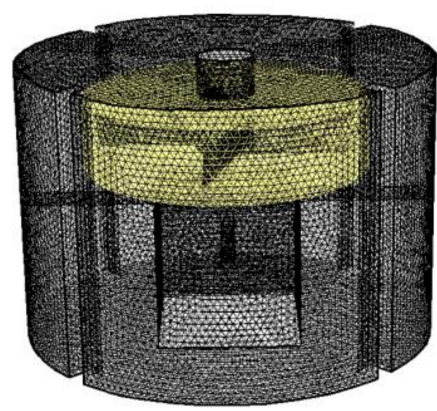

(b)

Figure 6. (a) Geometry of the experimental test; (b) computational mesh.

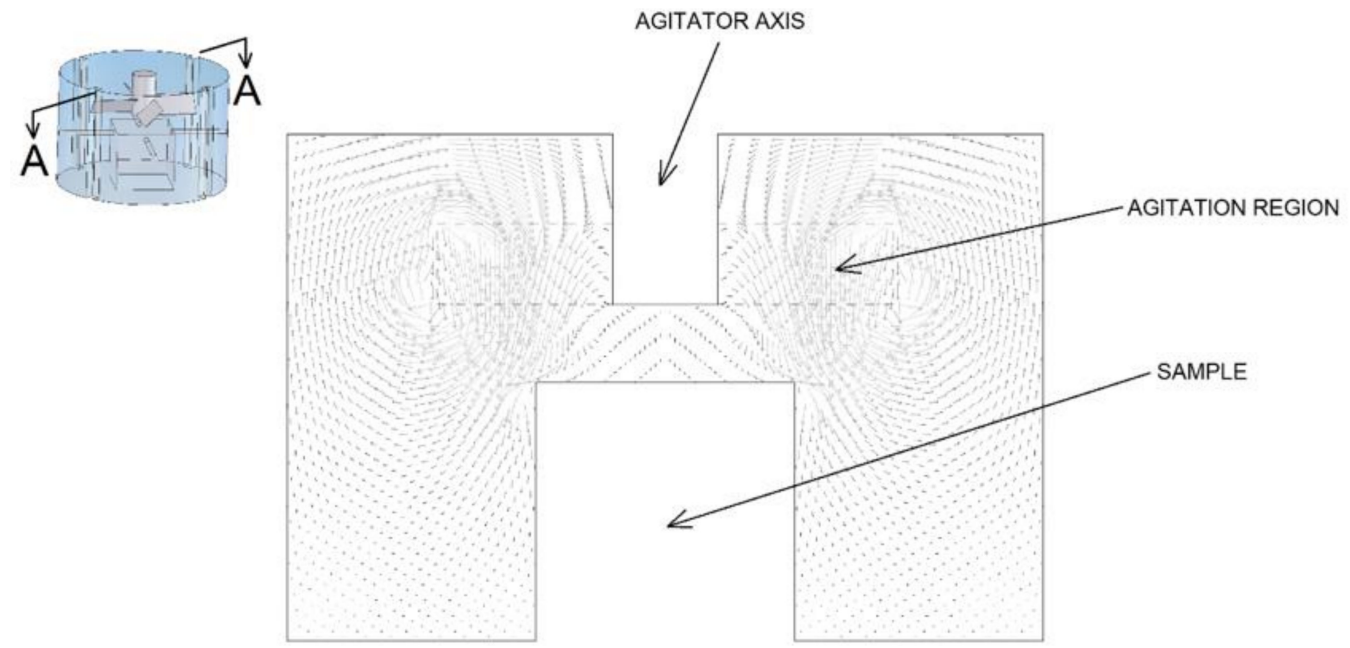

Figure 7. Velocity field in the A-A middle plane.

\section{Statistical Methods}

In this work, parametric and nonparametric regression models will be applied, in addition to analysis of variance techniques using univariate and functional data analysis (FDA) approaches.

Regression modeling allows us to describe and measure the relation of dependence between two or more variables. The response variable is always quantitative, whereas the independent variables can be quantitative or qualitative. This set of statistical techniques is used to measure the dependence between the degree of degradation of concrete for artificial reefs, on the one hand, and time and concrete formulation, on the other hand. The aim is to estimate the effect of time and formulation on the concrete erosive degradation, measured with the concrete weight loss percent variable. We intend to replace the concrete sand and/or cement with other more environmentally friendly materials such as mussel shells (waste product of the canning industry), taking into account that concrete will be used to develop artificial reefs.

A regression model can be described by:

$$
y_{i}=m\left(x_{i}\right)+\varepsilon_{i}, i=1,2, \ldots, n, \text { with } E\left(\varepsilon_{i}\right)=0
$$

where $y_{i}$ is the response variable values, estimated by the regression function $m$ as a function of the values of the independent variable, $t_{i}$, whereas $\varepsilon_{i}$ is the difference between the actual values and the fitted model, independent and identical distributed residuals with zero mean independent and identical distributed residuals. 
For parametric models, we can define the regression function as $M=\left\{m_{\theta}(\bullet) / \theta \in \Theta\right\}$, where $\theta$ is the vector of parameters, and $\Theta$ is a subset of $\mathbb{R}^{k}$. The goal of parametric regression is to provide a transfer function to estimate the response variable, which depends on a vector of parameters with physical-chemical meaning [26-31].

The relation between quantitative variables can be modeled by nonlinear functions such as an asymptotic function, which follows the expression:

$$
y=A s y m+(\operatorname{resp} 0-A s y m) \exp (-\exp (\operatorname{lrc}) x)
$$

where resp 0 is the initial value of $Y$, in this case corresponding to a time 0, Asym is the final horizontal assymptote, and $l r c$ is the natural logarithm of the rate constant (the half-life would be $\left.t_{0.5}=\log 2 / \exp (\operatorname{lrc})\right)$. This model has been used in other domains to explain the relationship between polymer mass loss and $\mathrm{pH}$ [34] or even to fit the learning curve of expanded Panama Canal [35]. Figure 8 shows the role of each parameter in the asymptotic model trend. In the present work, the asymptotic model is used to explain the mass loss as a function of time; in other words, it is used to fit the concrete degradation paths.

Effect of resp0 parameter

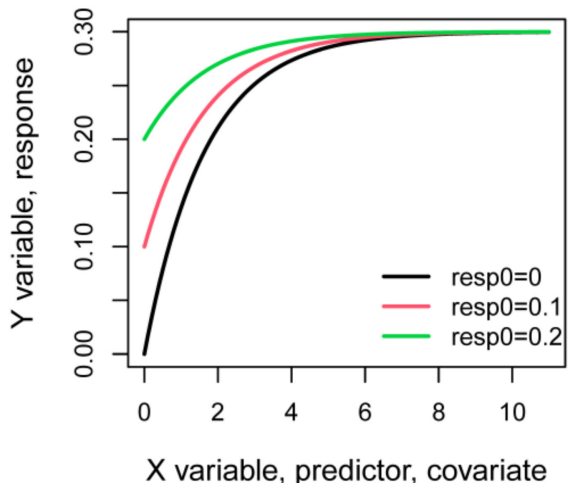

Effect of Irc parameter

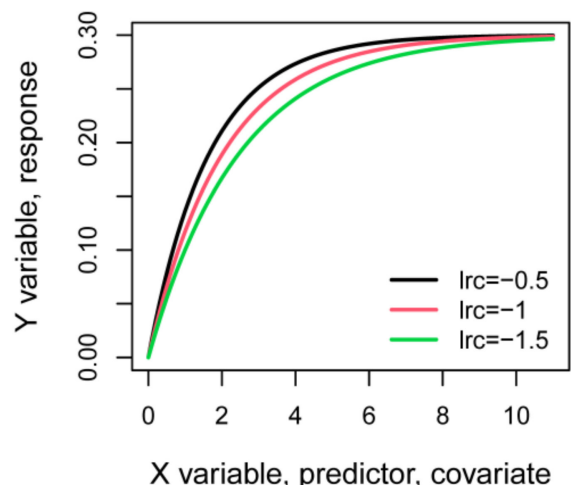

Effect of Asym parameter

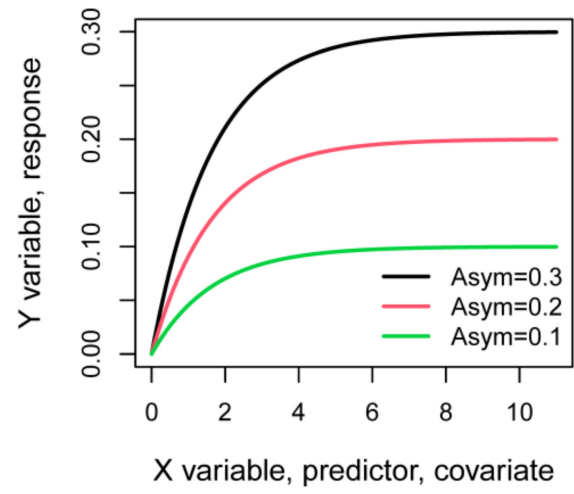

Reference asymptotic expression:

$y=0.3-(0-0.3) \exp (-\exp (-0.5) x)$

Figure 8. Role of the parameters within the nonlinear asymptotic regression model.

The above-mentioned parametric models are fixed effect models. We can add random effects to those parameters than can vary due to changes on the level of a factor. Namely, if we assume that there are different populations for which the regression trends are different (although they follow the same model type), we can estimate the population effects apart from the model residuals. In this work, the application of the so-called mixed effect regression models allows us to estimate the effect of the concrete formulation on the degradation and compare the degradation paths [34-38].

Nonparametric models are those that assume smooth effects of the independent variables on the response. They can be used when the underlying model of dependence is 
complex or unknown. Semiparametric models are also available, such as the generalized additive models (GAM). They predict the value of a response variable $Y$ (Gaussian, weibull, gamma, $t$, among many other distributions) as a function of parametric linear effects and smooth effects of the covariates, estimated by a wide range of spline basis [39]. If we assume that the response variable is Gaussian distributed, a GAM model of main effects (without interactions between variables) can be expressed by

$$
\hat{Y}=\beta_{0}+\sum_{i=1}^{k} \beta_{i} X_{i}+\sum_{j=1}^{l} s_{j}\left(T_{j}\right)
$$

in which $\hat{Y}$ is the estimated values of the response variable, whereas $X_{i}$ is the covariables, predictors, or independent variables that have a linear effect on the response through the $\beta_{i}$ parameters. In addition, we assume smooth effects of $T_{j}$ independent variables on the response, $s_{j}\left(T_{j}\right)$. These smooth effects can be fitted by a spline basis. Moreover, this family of models can also include the effect of the interaction of the different predictors.

In addition to regression analysis, techniques of analysis of variance (ANOVA) have been applied to identify, with statistical evidence, those concrete formulations for which the erosive degradation paths are different $[40,41]$. When each experimental result (response variable) is a curve, as the present case, we can use all the information obtained in the laboratory by using functional data analysis (FDA) approaches for the ANOVA test, also called FANOVA [37]. In the current work, the application of FANOVA tests is recommended from the fact that a response variable is also functional: smooth curves of weight loss as a function of time. When FANOVA is applied, following the Cuevas et al. [41] scheme, each functional datum is $X_{i j}(t)$ with $t \in[a, b]$, with $i$ the level of the factor and $j$ the run number $\left(j=1,2, \ldots, n_{i}\right.$, and $\left.i=1,2, \ldots, k\right)$. In this case, $X$ is the weight loss, $t$ the time, and the factor is the concrete formulation.

Taking into account that $E\left(X_{i}(t)\right)=m_{i}(t)$ and the covariance between two times $s$ and $t$ is $K i(s, t)$, the null hypothesis to test is $H_{0}=m_{1}=m_{1}=\ldots=m_{k}$, whereas the test statistic is $V_{n}=\sum_{i<j} n_{i}\left\|\bar{X}_{i}-\bar{X}_{j}\right\|^{2}$. Its probability distribution is estimated by nonparametric bootstrap procedures as shown in Cuevas et al. [42] and Tarrío-Saavedra et al. [37]. If $V_{n}$ is greater than a specific critical level $V_{\alpha}$, where $\alpha$ is the signification level, we will reject the null hypothesis, i.e., at least one group is different in terms of mass loss.

All the above-mentioned techniques have been applied using R software [43], specifically the mgcv [39] (https:/ / cran.r-project.org/web/packages/mgcv/, accessed on $20 \mathrm{Au}$ gust 2021), ggplot2 [44] (https: / / cran.r-project.org/web/packages/ggplot2/, accessed on 20 August 2021), fda.usc [45] (https://cran.r-project.org/web/packages/fda.usc/, accessed on 20 August 2021), nlme [46], and stats [35,43] packages.

\section{Results}

A comprehensive statistical analysis of the concrete erosive degradation results has been performed. The aim is to study the concrete resistance against erosion when different proportions of sand or/and cement are replaced by mussel shell. Indeed, apart from the chemical degradation, erosive degradation can play an important role in the durability of concrete structures under the sea such as artificial reefs. Consequently, developing experimental tests that evaluate the erosive degradation of concrete artificial reefs is necessary to measure their performance and, thus, to choose the best option before operational use. That is the case of the present study, where an experimental procedure is proposed, defined, and characterized.

One of the goals of the present methodology is to estimate the path of erosive degradation for each different concrete composition. To this regard, Figure 9 shows the mass loss percent with respect to time corresponding to each specimen. Each panel accounts for the erosive degradation paths for each level of mussel shell replacement. At least two replicates have been performed by factor level. Moreover, in order to estimate the degradation path, 
a GAM regression model based on shrinkage cubic regression splines [37] has been fitted to each degradation path.

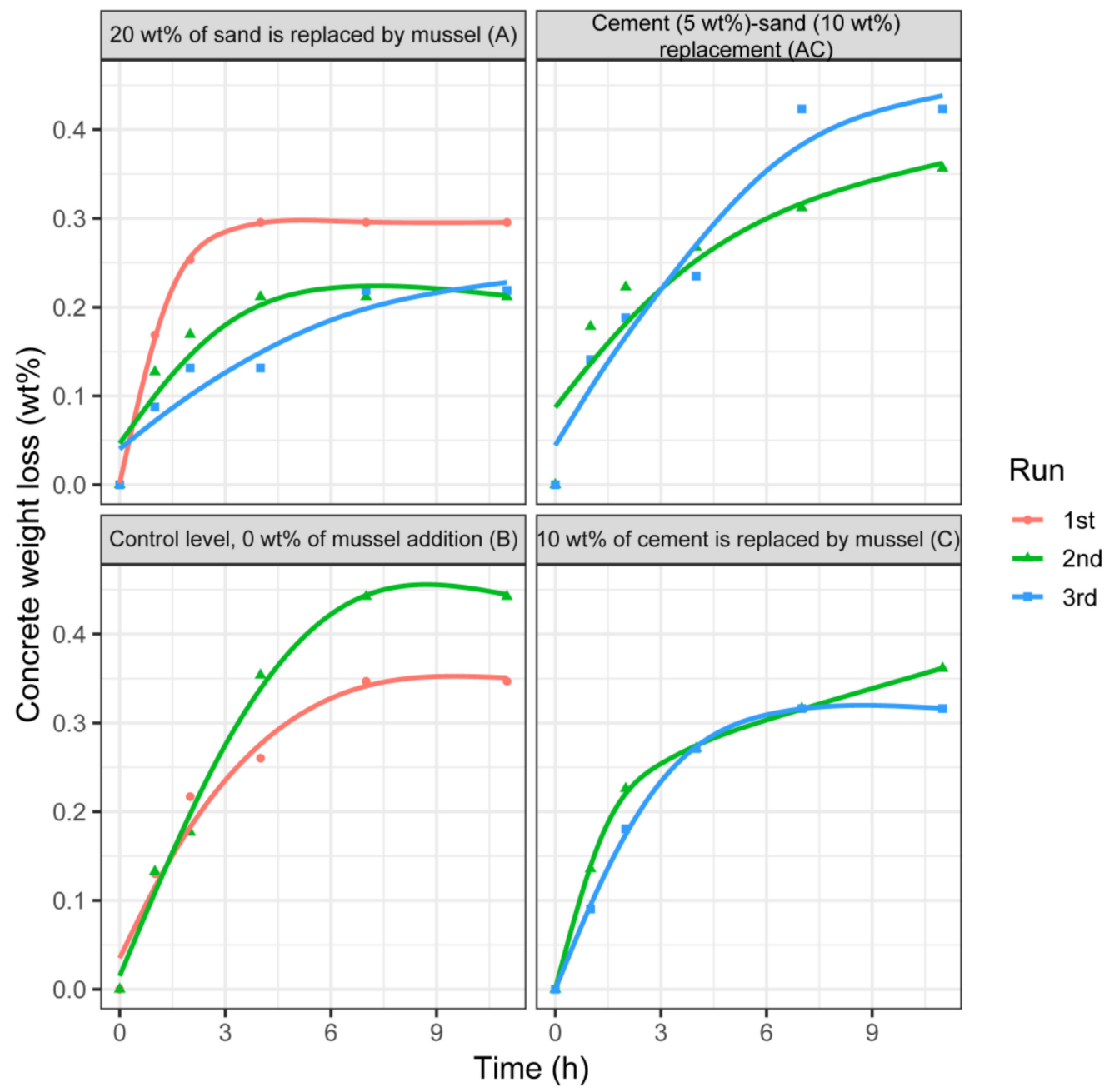

Figure 9. Degradation paths due to abrasive erosion of the different concrete formulations that are fitted by GAM models.

Figure 9 shows that the degradation paths tend to follow functional, asymptotic-type trends. We can also observe that the curves inside each panel (replicates for each level of the factor) tend to be closer to each other than to the curves of the other levels (in terms of scale, variability, and shape). Therefore, some differences in erosive degradation could be expected depending on the replacement with mussel shell. Figure 10 shows the GAM model fittings to the mass loss corresponding to each level of mussel replacement. The erosive degradation paths corresponding to the $\mathrm{AC}$ and $\mathrm{C}$ levels are quite similar to the $\mathrm{B}$ control level (standard concrete without mussel shells). Otherwise, the erosive degradation trend for A factor seems to have a lower scale, i.e., the samples where the $20 \mathrm{wt}$ \% of sand is replaced by mussel shells tend to have a higher resistance against erosive degradation.

We can observe a rapid mass loss at the beginning, but the degradation rate continuously decreases until the curve tends to saturate (see Figures 9 and 10). This fact tends to be more pronounced in the cases where sand and/or cement is replaced by mussel, above all in the specific case of A treatment, when the aggregate is replaced. The causes of these trends can be related to the abrasive erosion stages in hydraulic concrete described in Liu el al. [8]. They state that the mass loss caused by abrasive erosion in hydraulic concrete is a three-stage process. Initially, the pressure of the water molecules causes peeling of the concrete surface, prior to the abrasion. Subsequently, the impacts of the solids trans- 
ported by the water cause the removal of the mortar and the subsequent exposure of the coarse aggregates. Finally, aggregate removal occurs due to scraping and shearing actions. The described process could be affected by the proposed substitution of aggregate (fine and coarse) and cement by mussel shell. Thus, the effect of the shells (aragonite and calcite mixture) could affect the abrasion resistance (3rd stage). In addition, the shell precipitation due to gravity and shape could promote a surface layer of fine aggregate and cement that could be more easily abrasible (this could affect to the 1st and 2nd steps). Moreover, the loss of binder cement that provides cohesion to the mixture with shells could also promote the degradation during the three mentioned stages. The mass loss in the third stage could be defined by a small degradation rate.

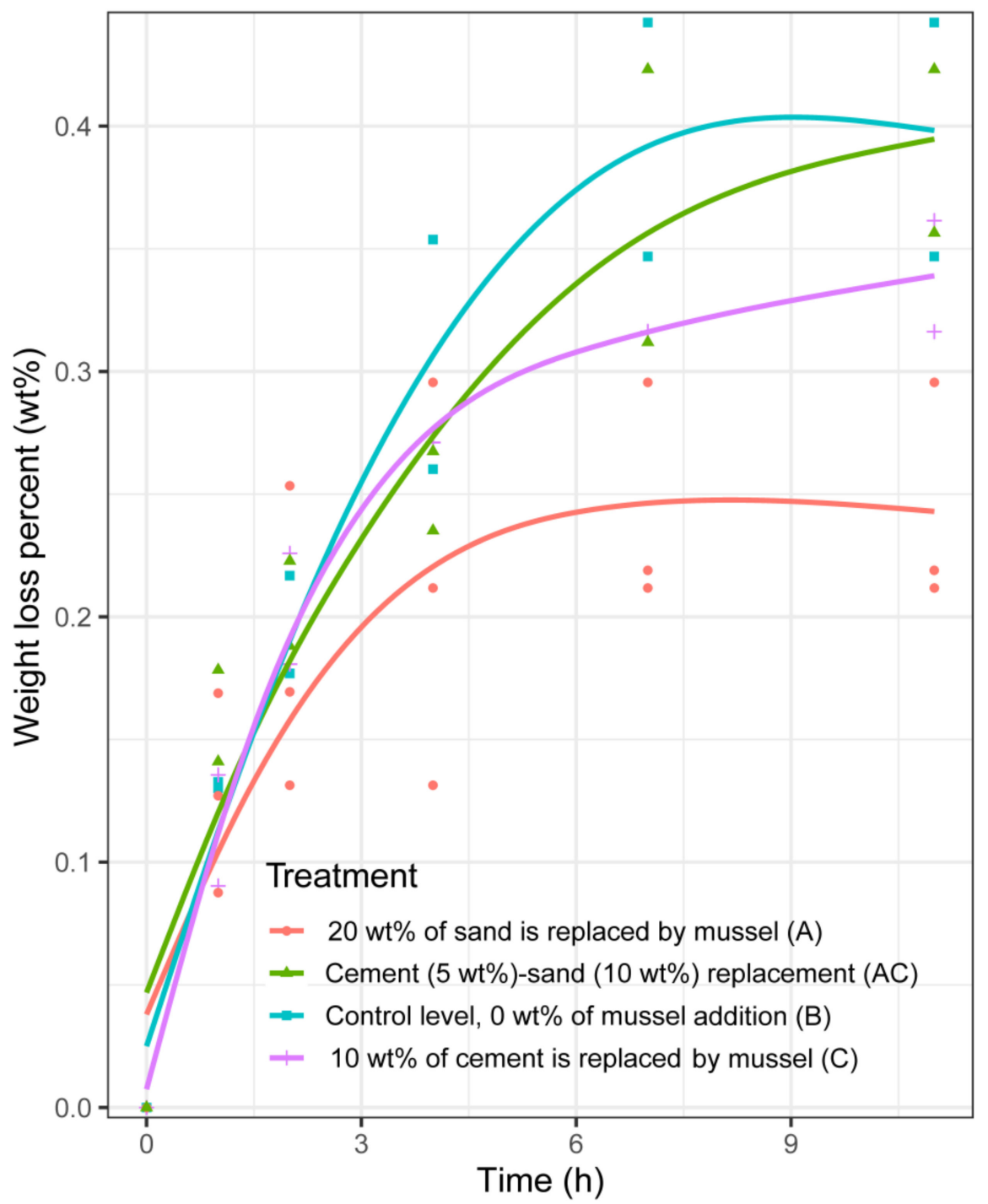

Figure 10. GAM model fittings to the weight loss corresponding to each level of mussel replacement factor.

The next step is to estimate a model able to estimate the effect of the time, on the one hand, and mussel addition, on the other hand, over the weight loss of the concrete used as artificial reef. The GAM models provide the goal of including both smooth and linear effects of quantitative and qualitative variables on the response. Therefore, the following GAM model based on four cubic regression splines has been fitted, obtaining the expression

$$
\text { We } \widehat{\text { ight loss }}=0.2374-0.0691 \times A-0.0085 \times A C-0.0303 \times C+s(\text { Time })
$$


with $R^{2}=0.84$, where $A, B, C$, and $A C$ are the linear effects of the levels of the treatment factor that accounts for the sand or/and cement mass replaced by mussel shell. The $s$ (Time) term is the nonparametric smooth effect of time on the weight loss percent. Table 3 shows the estimates and their signification analysis. The smooth effect of time and the linear effect of replacing the $20 \mathrm{wt} . \%$ of sand with mussel shells are significantly different from zero ( $p$-value $<0.05)$. Thus, the effect of time on erosive degradation (mass loss) seems to be asymptotic (see Figure 11a), whereas replacing $20 \mathrm{wt} . \%$ of sand by mussel tends to reduce the mass loss percent in $0.0691 \mathrm{wt} . \%$ with respect to the standard concrete (B). We also observe that replacing cement or cement and sand with mussel shells slightly tends to decrease the concrete weight loss, but the effect of these factors is not big enough to be significantly different from the control level (B), the concrete without mussel shells, as shown in Figure $11 \mathrm{~b}$ (the confidence intervals for $\mathrm{AC}$ and $\mathrm{C}$ parameters include the zero value). Therefore, concrete resistance against erosive degradation seems to depend on the concrete component partially replaced, on the one hand, and the replaced amount, on the other hand.

Table 3. Parameter estimates of GAM model for weight loss percent as a function of the concrete formulation and time, including signification analysis of parameters and goodness of fit measurements $\left(R^{2}\right)$.

\begin{tabular}{cccc}
\hline Predictors & Estimates & Conf. Interval & $p$-Value \\
\hline (Intercept) & 0.2374 & $0.2079-0.2670$ & $<0.001$ \\
A & -0.0691 & $-0.1072--0.0310$ & 0.001 \\
AC & -0.0085 & $-0.0502-0.0333$ & 0.685 \\
C & -0.0303 & $-0.0721-0.0114$ & 0.151 \\
Smooth term (Time) & & & $<0.001$ \\
\hline Observations & 54 & & \\
$R^{2}$ & 0.840 & & \\
\hline
\end{tabular}
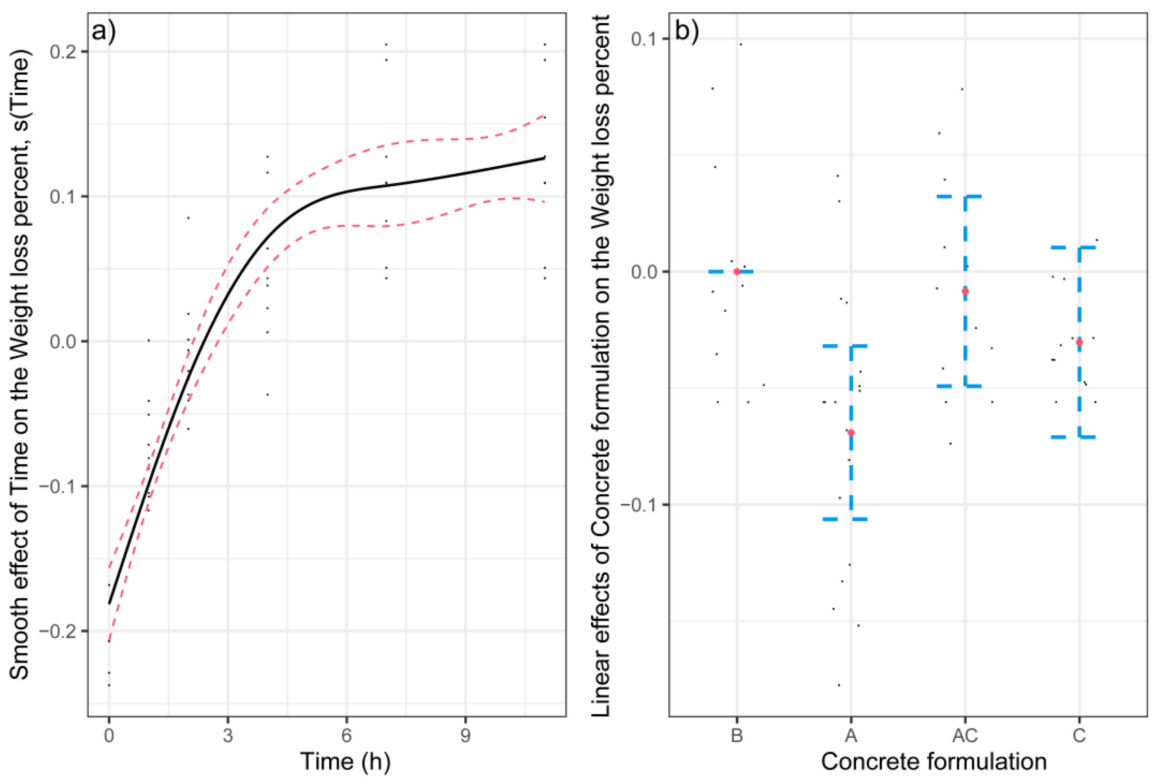

Figure 11. Effects time and concrete formulation on the weight loss percent estimated using the GAM model. (a) Smooth effect of the time (adding a 2 standard error width confidence bands. (b) $95 \%$ confidence intervals for the linear effects of concrete formulation, assuming the B level (concrete without mussel) as the reference. The A formulation is the treatment where the $20 \mathrm{wt} . \%$ of sand is replaced by mussel shells, the B level is the control treatment, in the $\mathrm{C}$ treatment, the $10 \mathrm{wt} . \%$ of cement has been replaced, whereas in the AC treatment, we replace the $10 \mathrm{wt} . \%$ of sand and the 5 wt.\% of cement. 
Since an asymptotic effect of time on weight loss has been identified, an asymptotic nonlinear parametric regression model is fitted. Its main advantage is to characterize the degradation of concrete and to compare the different formulations by studying their fitting parameters. Figure 12 shows the fittings of the asymptotic model to the degradation paths corresponding to each concrete formulation, including the model expression, the $R^{2}$, the fitted values, and the $95 \%$ confidence and prediction intervals for the fitted regression model. The parameters are significant from zero and the goodness of fit is high in terms of $R^{2}(>0.95)$. This support of the erosive degradation of concrete, using this experimental test, is asymptotic type; thus, the degree of degradation can be estimated by this parametric nonlinear model. We can compare the degradation paths of the different concrete formulations by developing the $95 \%$ confidence intervals for the parameters of the fitted asymptotic model, as shown in Figure 13. We can observe that the Asym parameter (it accounts for the horizontal asymptote for very large times) is significantly lower for A level with respect to the other formulations. In fact, the corresponding interval is not overlapped with the remaining. In other words, the weight loss percent is significantly lower when $20 \mathrm{wt} . \%$ of sand is replaced by mussel shells. Otherwise, the logarithm of the degradation rate, lrc, seems to be the same for all the formulations, but concrete of A level tends to degrade faster than the control concrete and the remaining formulations.
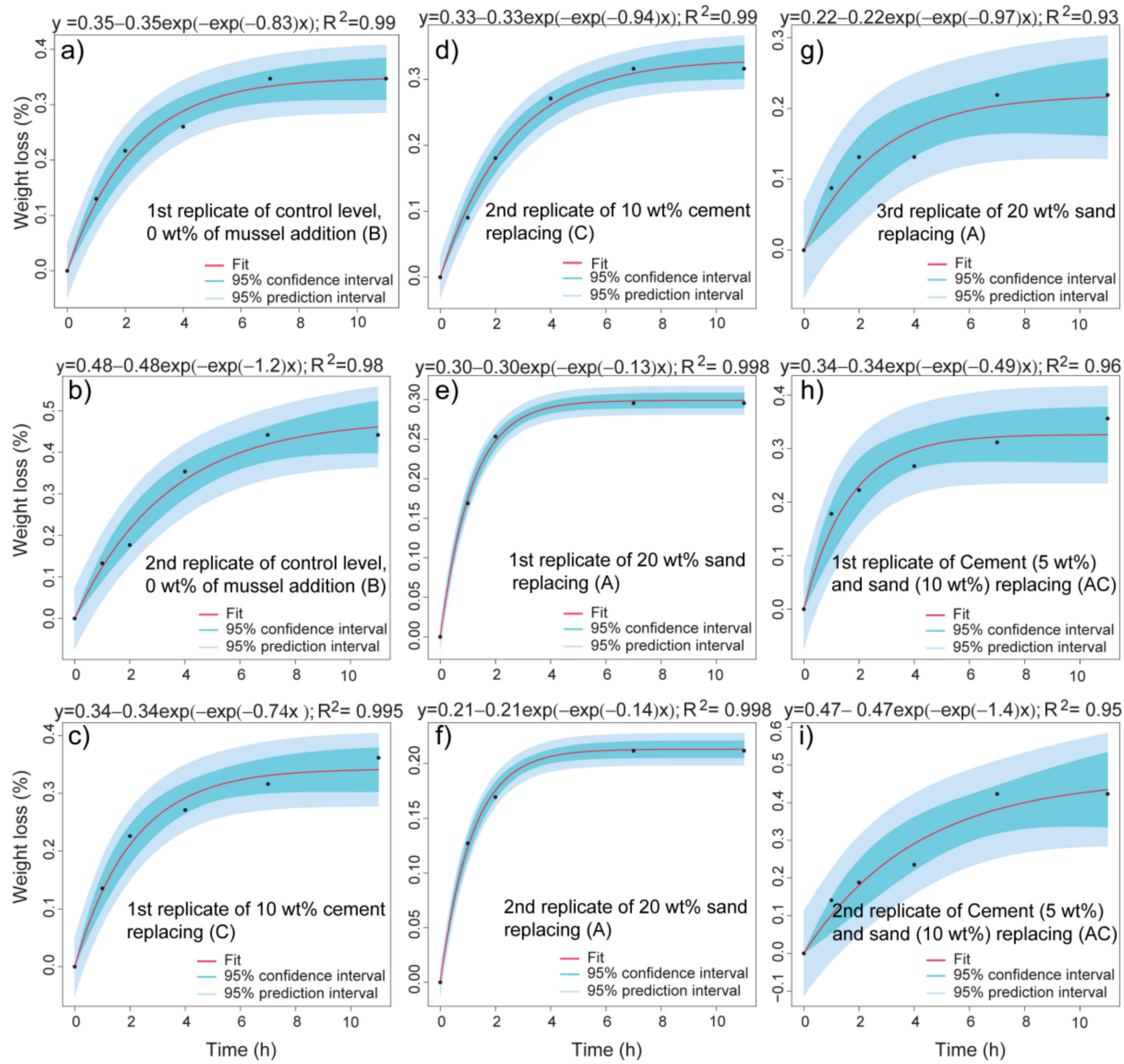

Figure 12. Fittings of the parametric nonlinear model based on the asymptotic function of the concrete weight loss (y) as a function of time $(\mathrm{x})$. The expression of the transfer function for weight loss and $R^{2}$ are included, in addition to the estimation and prediction confidence intervals for regression line and mass loss observations, respectively. The (a,b) panels correspond to the B formulation, the (c,d) fittings accounts for the C composition, the fittings to the A level curves are plotted in the $(\mathbf{e}-\mathbf{g})$ panels, whereas the $(\mathbf{h}, \mathbf{i})$ panels correspond to the fittings of the degradation paths of the AC formulation. 


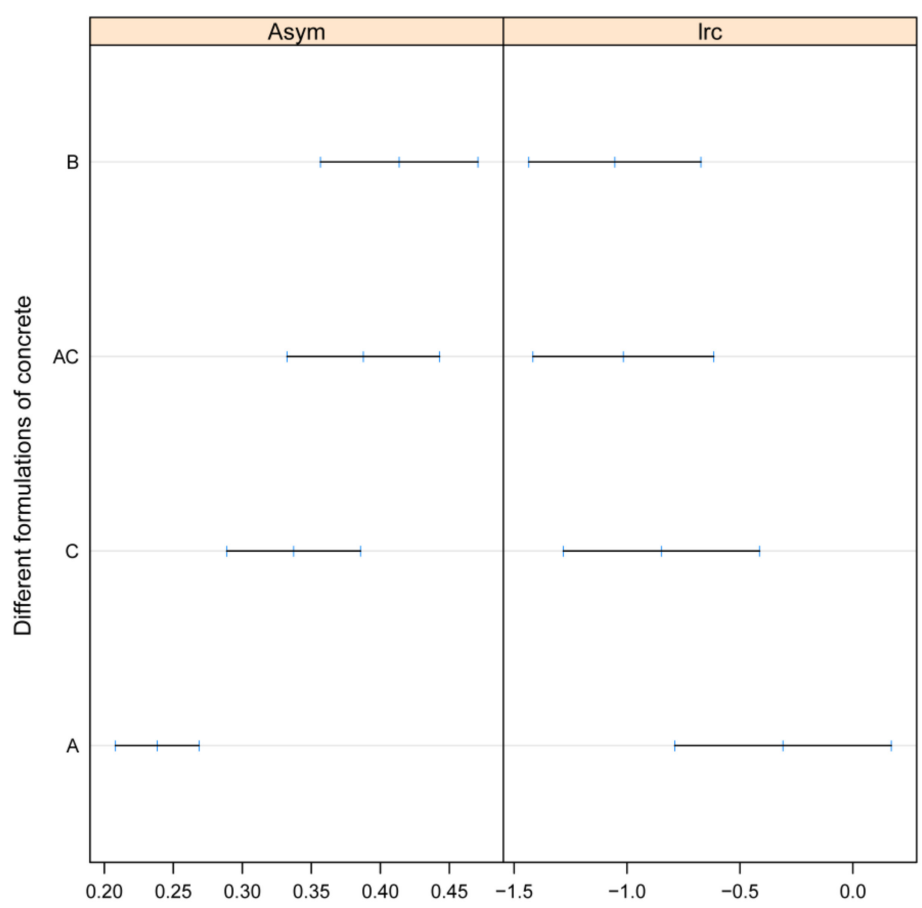

Figure 13. Ninety-five percent confidence intervals for the parameters of the asymptotic models fitted to the concrete mass loss as a function of time, for each concrete formulation. The A formulation is the treatment where the $20 \mathrm{wt} . \%$ of sand is replaced by mussel shells, the B level is the control treatment, in the $\mathrm{C}$ treatment, the $10 \mathrm{wt} \%$ of cement has been replaced, whereas in the AC treatment, we replace the $10 \mathrm{wt} . \%$ of sand and the $5 \mathrm{wt} . \%$ of cement.

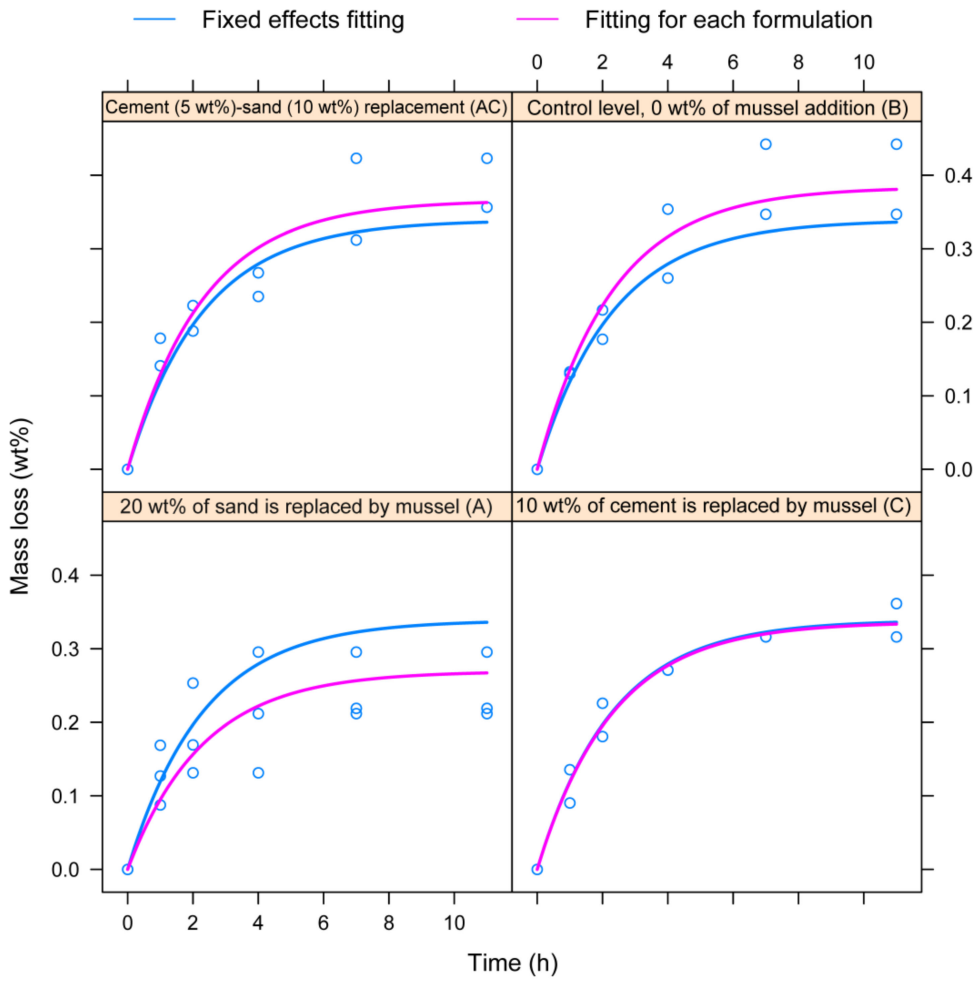

Figure 14. Graphical output of the mixed effect nonlinear asymptotic regression model. The fitting to the mass loss vs. time using all the observations is blue, whereas the fittings including the random effect for each concrete formulation are in pink. 
Taking into account that the main differences among concrete formulations are in the Asym parameter, we can fit a nonlinear regression model based on asymptotic function with the addition of random effect on the Asym parameter. This random effect is connected with the concrete formulation. This model allows us to compare the different degradation paths with respect to the fixed effect trend (expected value of weight loss estimated by fitting all the data). Figure 14 shows the graphical output of mixed effect regression model. The fixed effect model fitting is in blue, whereas the fitting including the random effect of each formulation of concrete is shown in pink. Formulations $B$ and $A C$ tend to lose more weight, while formulations $C$ and mainly A tend to lose less weight. All the differences between the formulation trends and the fixed effects fitting are very slight, except that corresponding to the A formulation.

In order to clearly identify the above-mentioned differences in degradation paths, analysis of variance (ANOVA) statistical techniques are usually applied. Taking into account the functional nature (curves) of the degradation data, a FANOVA test has been applied [45].

The goal of FDA is that it allows us to use all the information of the degradation path, not only one feature extracted from the curve as in the univariate approach. Before the application of FANOVA, we need to estimate the underlying model of the degradation paths, in other words, to estimate a continuous and soft curve for each degradation path. Therefore, we use the curves fitted by the asymptotic regression models as a functional response variable, whereas the independent variable is the factor dealing with the mussel shells replacement. The null hypothesis is $H_{0}=m_{A}=m_{B}=m_{A C}=m_{C}$, where $m_{i}$, with $i=A, B, C, A C$ are the functional mean for each level of the factor. It is tested using the $V_{n}$ statistic, $V_{n}=\sum_{i<j} n_{i}\left\|\bar{X}_{i}-\bar{X}_{j}\right\|^{2}$, where each functional datum is noted by $X_{i j}(t)$, with time $t \in[0,11], i$ accounts for the level of the factor $(i=1,2, \ldots, k)$, and $j$ is the run number $\left(j=1,2, \ldots, n_{i}\right.$, with $n_{i}=2$ or 3$)$. Figure 15 shows the results of the test, the left panel accounts for the functional means of mass loss corresponding to each level of the factor, whereas the center panel also shows the 100 bootstrap curves from which the distribution of $V_{n}$ statistic is estimated (see the right panel). The $p-$ value $=0.03<0.05$; thus, we can reject the null hypothesis at a confidence level of $\alpha=0.05$. Thus, we can assume that at least one level of mussel replacement is different from the others. In this case, if the functional means for the weight loss vs. time are observed (Figure 15a,b), we infer that the A group (20 wt.\% sand replaced with mussel shells) is significantly more resistant against erosive degradation.

Concrete mass loss follows an asymptotic trend. There is a rapid initial mass loss, but the degradation rate gradually decreases until the mass loss tends to reach a horizontal asymptote. This trend is similar to that of the wear depth with respect to time reported by Scott and Safiuddin [47] or the surface chloride concentration studied by Huang et al. [48]. The reasons for this trend are related to the characteristics and stages of the erosion process in the experimental test, which tries to emulate the marine environment. Thus, the rapid initial mass loss could be related to the first two stages of the erosion degradation (peeling by water molecules and mortar removal). The third stage, related to the removal of fine and coarse aggregates, could correspond to the part of the curves where the rate of mass loss is significantly reduced. There are differences in the shape of the curves depending on the concrete studied. As already noted, they may be due to the different hardness and resistance to permeability of the concrete formulation. The case of the concrete A in which a large amount of sand (20 wt.\%) is replaced by mussel shell stands out. It loses significantly less mass. This may be related, apart from what has already been pointed out, to the decrease in permeability by adding a significant amount of mussel shells $[6,13,19,21]$, which slows down the loss of aggregates. 

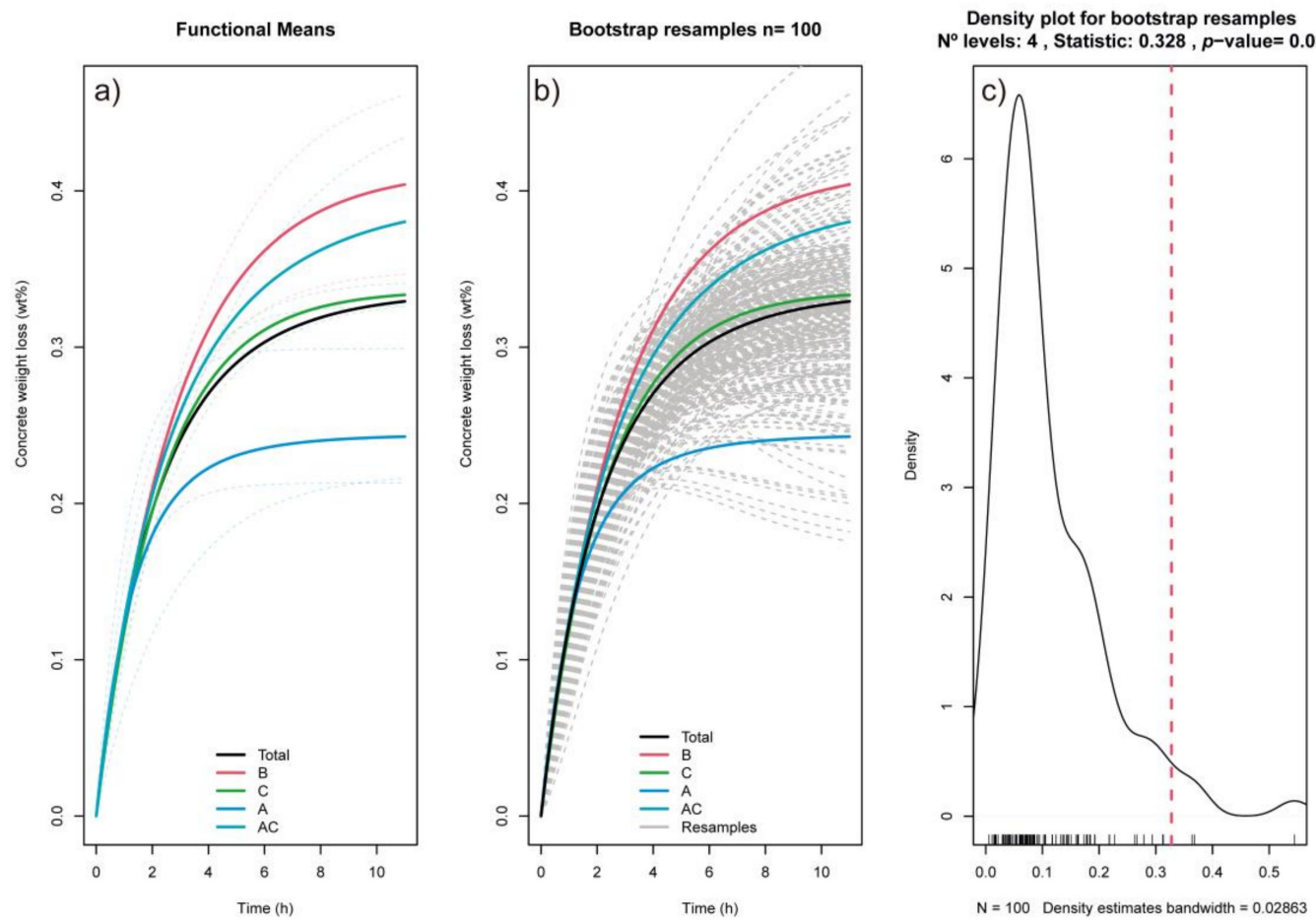

Figure 15. Results of the application of FANOVA test. (a) Functional means for the degradation paths corresponding to each concrete formulation. (b) Functional means in addition to all the degradation curves obtained by bootstrap resampling (100 resamples). (c) Estimates of the density function of the test statistic, value of the sample statistic (in red), and corresponding $p$-value. The A formulation is the treatment where the $20 \mathrm{wt} . \%$ is replaced by mussel shells, the B level is the control treatment, in the $\mathrm{C}$ treatment, the $10 \mathrm{wt} . \%$ of cement has been replaced, whereas in the AC treatment, we replace the $10 \mathrm{wt} . \%$ of sand and the $5 \mathrm{wt} . \%$ of cement by shells.

\section{Conclusions}

The present work intends to evaluate the introduction of mussel shells in concrete to be applied on artificial reefs in the Spanish coast. On the one hand, this material is more environmentally friendly, and on the other hand, it is an important residue of the canning industry in Galicia that it is necessary to reuse. For this purpose, we need to measure the erosive degradation behavior of the different types of concrete. Thus, a methodology to evaluate the erosive degradation performance in the maritime environment of concrete has been developed. It involves experimental testing, validated by CFD, and data analysis techniques to estimate and compare the degradation paths. A specific abrasive experimental testing has been developed to estimate the erosive degradation performance of concrete applied to new artificial reefs, which could be also used in other marine structures. The wear mechanisms involved in the present accelerated life test have been successfully modeled by CFD. The experimental conditions, involving the liquid-particle flow that can cause wear damage, have been defined. These conditions are in line with the actual conditions to which submerged materials may be subjected in marine environments.

The erosive degradation paths of different formulations of concrete have been obtained from the proposed experimental testing. The degree of degradation has been measured by the weight loss variable (wt.\%), and its trend with respect to time has been monitored.

A statistical semiparametric GAM regression model has been fitted, and the effect of time and the addition of mussel shells have been estimated. As a result, the effect of time in the weight loss by erosion is asymptotic type. Moreover, the effect of replacing sand and/or cement by mussel shells is only significant when the replaced quantity of sand is relatively high $(20 \mathrm{wt} . \%)$. In this case, the resistance against erosive degradation is slightly high. The mass loss is between 0.1072 and $0.0310 \mathrm{wt} . \%$ lower than the corresponding to 
the control treatment $\mathrm{B}$. This can be connected with a reduction in permeability to water, among other possible causes that should be studied in more detail. The results of FANOVA application have supported that only the replacement of relatively high quantities of sand produces slightly significant differences in erosive degradation. In fact, these samples tend to lose less quantity of mass (between 0.2080238 wt. $\%$ and $0.2686441 \mathrm{wt} . \%$, at a confidence level of $95 \%$ ) and at a higher rate (in the first stage of degradation), as shown by, mainly, the Asym (final mass loss) and also lrc (degradation rate) parameters of the fitted nonlinear asymptotic regression models.

In all the remaining cases (replacements of the 5-10 wt.\% of sand and cement), the effect of mussel replacement on erosive degradation is not significant. These results encourage the use of mussel shells in the composition of concrete, taking into account that we obtain the same degradation properties, even more so considering an important residue in the canning industry (and part of the seabed) that can be valorized.

Author Contributions: Conceptualization, C.C., J.L.M., L.C., and J.C.Á.; methodology, C.C. and J.L.M.; software, M.I.L. and J.T.-S.; validation, J.T.-S.; formal analysis, C.C., J.L.M., and A.-M.D.-D.; resources, J.C.Á.; writing—original draft preparation, C.C., J.L.M., M.I.L., and J.T.-S.; writing—review and editing, L.C., C.C., J.L.M., M.I.L., and J.T.-S.; project administration, L.C.; funding acquisition, L.C. All authors have read and agreed to the published version of the manuscript.

Funding: This research was funded by Xunta de Galicia through the project CN-10MMA003CT. This study was also funded through the collaboration agreement between Xunta de Galicia (Convenio de colaboración entre a Xunta de Galicia, a Universidade da Coruña e a Fundación da Universidade da Coruña para dar continuidade ao Proxecto de investigación de arrecife artificial—PROARR), Universidade da Coruña and the Universidade da Coruña Foundation (FUAC) to give continuity to the previous project. The research of Javier Tarrío-Saavedra has been supported by MINECO grant MTM2017-82724-R, Ministerio de Ciencia e Innovación grant PID2020-113578RB-100, and by the Xunta de Galicia (Grupos de Referencia Competitiva ED431C-2020-14 and Centro de Investigación del Sistema universitario de Galicia ED431G2019/01), all of them through the ERDF.

Institutional Review Board Statement: Not applicable.

Informed Consent Statement: Not applicable.

Data Availability Statement: The data presented in this study are available on request from the corresponding author.

Acknowledgments: The authors warmly thank the work of the two reviewers. All their help and guidance have significantly improved the present study.

Conflicts of Interest: The authors declare no conflict of interest.

\section{References}

1. Carral, L.; Lamas-Galdo, M.I.; Rodríguez-Guerreiro, M.J.; Vargas, A.; Álvarez-Feal, C.; López, I.; Carballo, R. Configuration Methodology for a Green Variety Reef System (AR Group) Based on Hydrodynamic Criteria-Application to the Ría de Ares-Betanzos. Estuar. Coast. Shelf Sci. 2021, 252, 107301. [CrossRef]

2. Carral, L.; Alvarez-Feal, C.; Jesús Rodríguez-Guerreiro, M.; Vargas, A.; Arean, N.; Carballo, R. Methodology for Positioning a Group of Green Artificial Reef Based on a Database Management System, Applied in the Estuary of Ares-Betanzos (Nw Iberian Peninsula). J. Clean. Prod. 2019, 233, 1047-1060. [CrossRef]

3. Carral, L.; Cartelle Barros, J.J.; Carro Fidalgo, H.; Camba Fabal, C.; Munín Doce, A. Greenhouse Gas Emissions and Energy Consumption of Coastal Ecosystem Enhancement Programme through Sustainable Artificial Reefs in Galicia. Int. J. Environ. Res. Public Health 2021, 18, 1909. [CrossRef] [PubMed]

4. Convention for the Protection of the Marine Environment of the North-East Atlantic, 1992. OSPAR Convention. Available online: https: / / www.ospar.org/ convention (accessed on 20 August 2021).

5. El Biriane, M.; Barbachi, M. State-of-the-Art Review on Recycled Mussel Shell Waste in Concrete and Mortar. Innov. Infrastruct. Solut. 2021, 6, 29. [CrossRef]

6. Tayeh, B.A.; Hasaniyah, M.W.; Zeyad, A.M.; Yusuf, M.O. Properties of Concrete Containing Recycled Seashells as Cement Partial Replacement: A Review. J. Clean. Prod. 2019, 237, 117723. [CrossRef]

7. Barbachi, M.; Imad, A.; Jeffali, F.; Boudjellal, K.; Bouabaz, M. Physical Characterization of Sea Shell for a Concrete Formulation. J. Mater. Environ. Sci. 2017, 8, 6.

8. Liu, Y.-W.; Yen, T.; Hsu, T.-H. Abrasion Erosion of Concrete by Water-Borne Sand. Cem. Concr. Res. 2006, 36, 1814-1820. [CrossRef] 
9. Lima, J.S.; Zalmon, I.R.; Love, M. Overview and Trends of Ecological and Socioeconomic Research on Artificial Reefs. Mar. Environ. Res. 2019, 145, 81-96. [CrossRef]

10. Bedoya Gutierréz, M.A.; Tobón, J.I.; Correa-Herrera, T.; Correa-Rendón, J.D. Biological and Physicochemical Evaluation of Mortar as Substrate for Manufacturing Artificial Reef. Bol. Cienc. Tierra 2016, 40, 55-63. [CrossRef]

11. Huang, X.; Wang, Z.; Liu, Y.; Hu, W.; Ni, W. On the Use of Blast Furnace Slag and Steel Slag in the Preparation of Green Artificial Reef Concrete. Constr. Build. Mater. 2016, 112, 241-246. [CrossRef]

12. Walles, B.; Troost, K.; van den Ende, D.; Nieuwhof, S.; Smaal, A.C.; Ysebaert, T. From Artificial Structures to Self-Sustaining Oyster Reefs. J. Sea Res. 2016, 108, 1-9. [CrossRef]

13. Carral, L.; Alvarez-Feal, J.C.; Tarrio-Saavedra, J.; Rodriguez Guerreiro, M.J.; Fraguela, J.Á. Social Interest in Developing a Green Modular Artificial Reef Structure in Concrete for the Ecosystems of the Galician Rías. J. Clean. Prod. 2018, 172, 1881-1898. [CrossRef]

14. Mijan, N.A.; Sahari, F.; Yusoff, S.B.M. Cockle Shell As An Alternative Construction Material For Artificial Reef. In Proceedings of the 3rd Proceeding International Conference on Applied \& Creative Arts: Beyond Boundaries (ICACA), Kota Samarahan, Malaysisa, 6 July 2011; Faculty of Applied and Creative Art, UNNIMAS: Kota Samarahan, Malaysia, 2011.

15. Yu, Y.; Gao, W.; Castel, A.; Liu, A.; Chen, X.; Liu, M. Assessing External Sulfate Attack on Thin-Shell Artificial Reef Structures under Uncertainty. Ocean. Eng. 2020, 207, 107397. [CrossRef]

16. Carral, L.; Camba Fabal, C.; Lamas Galdo, M.I.; Rodríguez-Guerreiro, M.J.; Cartelle Barros, J.J. Assessment of the Materials Employed in Green Artificial Reefs for the Galician Estuaries in Terms of Circular Economy. Int. J. Environ. Res. Public Health 2020, 17, 8850. [CrossRef]

17. Labarta, U.; Fernández-Reiriz, M.J. The Galician Mussel Industry: Innovation and Changes in the Last Forty Years. Ocean. Coast. Manag. 2019, 167, 208-218. [CrossRef]

18. Martinez-Albores, A.; Lopez-Santamarina, A.; Rodriguez, J.A.; Ibarra, I.S.; Del Carmen Mondragón, A.; Miranda, J.M.; Lamas, A.; Cepeda, A. Complementary Methods to Improve the Depuration of Bivalves: A Review. Foods 2020, 9, E129. [CrossRef]

19. Sun, J.; Chen, Z. Influences of Limestone Powder on the Resistance of Concretes to the Chloride Ion Penetration and Sulfate Attack. Powder Technol. 2018, 338, 725-733. [CrossRef]

20. Shabery Sainudin, M.; Hazurina Othman, N.; Shahidan, S. Performance of Concrete Containing Mussel Shell (Perna Viridis) Ash under Effect of Sodium Chloride Curing. IOP Conf. Ser. Mater. Sci. Eng. 2019, 601, 012033. [CrossRef]

21. Higgins, D.D. Increased Sulfate Resistance of Ggbs Concrete in the Presence of Carbonate. Cem. Concr. Compos. 2003, 25, 913-919. [CrossRef]

22. Barnaby, C. An Investigation into the Reuse of Organic Waste Produced by the New Zealand Mussel Industry. Master of Applied Science, Auckland University of Technology, Auckland, New Zealand, January 2004.

23. Gonzalez, B.; Carro, D.; Martínez-Abella, F.; Martínez, C.; Seara-Paz, S. Effects of Seashell Aggregates in Concrete Properties. Acad. J. Civ. Eng. 2015, 33, 376-382. [CrossRef]

24. Sonebi, M. Utilization of Micro-Indentation Technique to Determine the Micromechanical Properties of ITZ in Cementitious Materials. In Proceedings of the Nanotechnology of Concrete: Recent Developments and Future Perspectives, Denver, CO, USA, 7 November 2006; American Concrete Institute: Farmington Hills, MI, USA, 2008.

25. Omoding, N.; Cunningham, L.; Lane-Serff, G.F. Review of Concrete Resistance to Abrasion by Waterborne Solids. Mater. J. 2020, 117, 41-52. [CrossRef]

26. Kryžanowski, A.; Mikoš, M.; Šušteršic, J.; Planinc, I. Abrasion Resistance of Concrete in Hydraulic Structures. Mater. J. 2009, 106, 349-356.

27. ASTM C1138. Standard Test Method for Abrasion Resistance of Concrete (Underwater Method), 2012. ASTM C1138M-19. Available online: https://www.astm.org/Standards/C1138M.htm (accessed on 20 August 2021).

28. Messa, G.V.; De Lima Branco, R.; Filho, J.G.D.; Malavasi, S. A Combined CFD-Experimental Method for Abrasive Erosion Testing of Concrete. J. Hydrol. Hydromech. 2018, 66, 121-128. [CrossRef]

29. Horszczaruk, E. The Model of Abrasive Wear of Concrete in Hydraulic Structures. Wear 2004, 256, 787-796. [CrossRef]

30. Chinese Water Conservancy and Electric Power Press SL352. Test Code for Hydraulic Concrete, 2006. SL 352-2006. Available online: https:/ / www.chinesestandard.net/PDF/English.aspx/SL352-2006 (accessed on 20 August 2021).

31. Wang, X.; Luo, S.; Liu, G.; Zhang, L.; Wang, Y. Abrasion Test of Flexible Protective Materials on Hydraulic Structures. Water Sci. Eng. 2014, 7, 106-116.

32. Nanjing Water Conservancy Research Institute DL/T 5150-2017, Test Code for Hydraulic Concrete; National Energy Board: Beijing, China, 2017.

33. Dandapat, R.; Deb, A. A Probability Based Model for the Erosive Wear of Concrete by Sediment Bearing Water. Wear 2016, 350-351, 166-181. [CrossRef]

34. Robles-Bykbaev, Y.; Tarrío-Saavedra, J.; Quintana-Pita, S.; Díaz-Prado, S.; García Sabán, F.J.; Naya, S. Statistical Degradation Modelling of Poly(D,L-Lactide-Co-Glycolide) Copolymers for Bioscaffold Applications. PLoS ONE 2018, 13, e0204004. [CrossRef]

35. Carral, L.; Tarrío-Saavedra, J.; Sáenz, A.V.; Bogle, J.; Alemán, G.; Naya, S. Modelling Operative and Routine Learning Curves in Manoeuvres in Locks and in Transit in the Expanded Panama Canal. J. Navig. 2021, 74, 633-655. [CrossRef]

36. Janeiro-Arocas, J.; Tarrío-Saavedra, J.; López-Beceiro, J.; Naya, S.; López-Canosa, A.; Heredia-García, N.; Artiaga, R. Creep Analysis of Silicone for Podiatry Applications. J. Mech. Behav. Biomed. Mater. 2016, 63, 456-469. [CrossRef] 
37. Robles-Bykbaev, Y.; Naya, S.; Díaz-Prado, S.; Calle-López, D.; Robles-Bykbaev, V.; Garzón, L.; Sanjurjo-Rodríguez, C.; Tarrío-Saavedra, J. An Artificial-Vision- and Statistical-Learning-Based Method for Studying the Biodegradation of Type I Collagen Scaffolds in Bone Regeneration Systems. PeerJ 2019, 7, e7233. [CrossRef]

38. Pinheiro, J.C.; Bates, D.M. Mixed-Effects Models in S and S-PLUS, 1st ed.; Springer: New York, NY, USA, 2006.

39. Wood, S.N. Generalized Additive Models: An Introduction with R, 2rd ed.; Chapman \& Hall/CRC: Boca Raton, FL, USA, 2017.

40. Tarrío-Saavedra, J.; Naya, S.; Francisco-Fernández, M.; Artiaga, R.; Lopez-Beceiro, J. Application of Functional ANOVA to the Study of Thermal Stability of Micro-Nano Silica Epoxy Composites. Chemom. Intell. Lab. Syst. 2011, 105, 114-124. [CrossRef]

41. Cuevas, A.; Febrero, M.; Fraiman, R. An Anova Test for Functional Data. Comput. Stat. Data Anal. 2004, 47, 111-122. [CrossRef]

42. Ríos-Fachal, M.; Tarrío-Saavedra, J.; López-Beceiro, J.; Naya, S.; Artiaga, R. Optimizing Fitting Parameters in Thermogravimetry. J. Therm. Anal. Calorim. 2014, 116, 1141-1151. [CrossRef]

43. R Foundation for Statistical Computing R Core Team. R: A Language and Environment for Statistical Computing. 2021. Available online: https: / / www.r-project.org/ (accessed on 20 August 2021).

44. Wickham, H. ggplot2: Elegant Graphics for Data Analysis, 1st ed.; Springer: New York, NY, USA, 2009.

45. Febrero-Bande, M.; de la Fuente, M.O. Statistical Computing in Functional Data Analysis: The R Package fda.usc. J. Stat. Softw. 2012, 51, 1-28. [CrossRef]

46. Pinheiro, J.; Bates, D.; DebRoy, S.; Sarkar, D. R Core Team Nlme: Linear and Nonlinear Mixed Effects Models. Available online: https:/ / cran.r-project.org/web/packages/nlme/ (accessed on 20 August 2021).

47. Scott, B.D.; Safiuddin, M. Abrasion resistance of concrete-Design, construction and case study. Concr. Res. Lett. 2015, 6, 136-148.

48. Huang, D.; Niu, D.; Zheng, H.; Su, L.; Luo, D.; Fu, Q. Study on Chloride Transport Performance of Eco-Friendly Coral Aggregate Concrete in Marine Environment. Constr. Build. Mater. 2020, 258, 120272. [CrossRef] 